\title{
A traditional Asian diet modified to meet nutritional requirements of diabetes, has anything changed? A cross-sectional dietary survey
}

\author{
Arjuna Medagama* and Heshan Widanapathirana
}

\begin{abstract}
Background: Medical nutrition therapy is the cornerstone of managing type 2 diabetes mellitus. Meals that are modified to suit diabetes should be culturally acceptable, retain palatability and conform to the energy requirements of diabetes. The objective of this study was to find if the dietary patterns of Sri Lankan type 2 diabetes patients have changed from the traditional serving characteristics to align with dietary recommendations of diabetes, while retaining palatability and cultural acceptability.

Methods: A cross-sectional survey was performed at a multi-ethnic, tertiary care diabetes facility in Sri Lanka. Fruits, vegetables, starch, pulses, dairy and added sugars in diet were assessed with portion size estimation using a 24-h dietary recall according to standard methods.

Results: The meals consumed by participants were "traditional" and retained palatability. Rice contributed to 93\% of the starch-based food types. Ninety-two percent consumed starch in excess of the daily recommendation. Fruit and vegetable consumption was 1.3 and 2.8 servings per day, with $33 \%$ failing to consume any fruit. Seventy-four percent and $65 \%$ of participants failed to consume the minimum daily recommended number of fruit and vegetable servings. Only $1 \%$ of participants consumed added sugar.

Conclusions: The Sri Lankan diabetes diet is a portion-restricted version of the traditional meal that retained cultural acceptability and palatability. A large proportion of patients still consume carbohydrates in excess of the recommendations. Although there is an increasing trend towards fruit and vegetable consumption, the majority still fell short of the recommendations.
\end{abstract}

Keywords: Type 2 diabetes, Food consumption, Dietary survey, Serving size, Portion size

\section{Background}

Medical nutrition therapy is an essential component in the management of diabetes and probably of value in reducing new complications. Therefore, it is essential to know the dietary patterns of diabetes patients.

The Asian region is currently in the midst of a diabetic pandemic, and it is believed that dietary patterns are partly responsible for this. Rice is the principal staple of the Asian diet, and other carbohydrates are consumed in lesser quantities. The high consumption of white rice is thought to increase the incidence and prevalence of diabetes [1]. A recent meta-analysis has shown clear

\footnotetext{
* Correspondence: arjuna.medagama@gmail.com

Department of Medicine, Faculty of Medicine, University of Peradeniya, Galaha Road, Peradeniya 20400, Sri Lanka
}

evidence that higher consumption of white rice (with a high glycaemic index) increases the incidence of diabetes in Asian populations [2].

Sri Lanka has a population of 21 million and a rapidly increasing burden of diabetes. The current prevalence of diabetes is estimated to be $10.3 \%$ with a projected prevalence of $13.9 \%$ for the year 2025 [3]. The increase in prevalence is seen in both rural and urban areas [3,4].

The joint position statements by the American Diabetes Association (ADA) and the European Association for the Study of Diabetes encourage the development of treatment plans centred on racial and ethnic differences. However, this recommendation seems to be poorly adhered to partly because many communities exclude culturally relevant food from dietary counselling and 
thereby effectively preventing the patients from sharing the same food as the rest of the family members [5]. Carbohydrates comprise the bulk of the energy requirement of any meal and are contributed by the consumption of cereals, pulses, fruits and vegetables, and the ADA encourages such varied sources of nutrition [6]. The Asian diet in general and Sri Lankan in particular is a high-carbohydrate low-fat diet.

The traditional Sri Lankan diet consists of threefourth plate of rice topped up with several curries. The use of fresh vegetables or fruits in isolation is rare, and the average day is centred on the 3 main meals of breakfast, lunch and dinner.

Jayawardena et al. showed a clear predominance of starch and added sugar in the Sri Lankan adult diet with very low consumption of fruits, vegetables, pulses and dairy [7], in spite of Sri Lanka producing an abundance of fruits, vegetables and pulses.

A particular problem encountered in a multi-racial, multi-cultural community is the translation of the energy requirements from each food category, expressed as proportion of the daily energy requirement, in guidelines into the everyday parlance of the patient.

The aim of this study was to find if the dietary patterns of a cohort of Sri Lankan type 2 diabetes patients have changed significantly from the traditional serving characteristics to suit that of diabetes following counselling, while retaining palatability cultural acceptability.

\section{Methods}

One hundred and twenty-three randomly selected type 2 patients with diabetes, attending the diabetes facility at Teaching Hospital, Peradeniya, Sri Lanka, between May and August 2014, were recruited for this study. The diabetes facility caters to over 2,000 type 2 patients from a multi-ethnic background, and a sample size of 123 was deemed adequate for the population. Ethical review for the study was obtained from the Ethics review committee of the Faculty of Medicine, University of Peradeniya. At time of recruitment, verbal consent was obtained from the participants and was formally recorded. An information sheet outlined the objectives as well as how the data would be used in anonymity for research purposes. Inclusion criteria included age more than 18 years, type 2 diabetes mellitus for over 6 months and having had formal nutrition counselling by a trained nurse in diabetes. Exclusion criterion included the inability to give consent due to physical, verbal or intellectual impairment.

\section{Procedure}

Two independent interviewers performed a 24-h dietary recall on the recruited patients. The data was recorded onto a preprinted format, which allowed either weight of the portion or size of the portion using the methods described below to be entered. The gathered data from the 2 interviewers were compared at the end of the day, and if there was any discrepancy, the patient was reinterviewed on another day. The patients were asked to recall what they ate during the preceding $24 \mathrm{~h}$ in chronological order. The interviewers used common household utensils such as plates of varying sizes, bowls, cups, spoons and glasses to determine portion sizes. These were available in a variety of sizes for patients to go through and determine which best reflected their portion size. In instances that patients were able to recall weight of their portion, this was recorded. Common foods such as rice and curries were available within the interviewers' room and the patients were asked to serve their usual portion size onto a plate, and the weight of the portion was recorded. This was then compared with the portion size they had recalled using the common household utensils.

All the foods recorded from the 24-h dietary recall were categorized under seven categories: (i) cereals or equivalents (starchy food), (ii) vegetables, (iii) fruits, (iv) meat or alternatives, (v) pulses, (vi) dairy and (vii) added sugars.

\section{Portion size determination}

Data from the dietary recall was assigned to one of the seven categories mentioned above. In cases where the food were a mixture several food types, they were disaggregated and the component ingredients assigned to one of the seven categories mentioned above. Similar method was used in a previous survey on a similar cultural background [7]. The weight of the food in grams divided by the weight of one portion in grams or the amount in household measures (cup, spoon) divided by amount of one portion depicted in household measure was used to determine the amount of portions consumed in each food category. The number of portions thus determined in each category was then totaled and divided by the number of participants to calculate the mean number of portions consumed for a specific category. The mean number of portions was then analysed to reflect their relationship to national guidelines by gender.

Using the dietary recall, the mean number of servings consumed at each meal for the seven food categories was recorded. These were breakfast, morning snack, lunch, afternoon snack and dinner, respectively. The food types that contributed to the daily carbohydrate consumption were totaled, and the fraction derived from the main staple (rice) was calculated. The palatability and cultural acceptability of the food consumed was recorded from the respondents as either acceptable or not. 


\section{Data analysis}

The data analysis was conducted using the Statistical Package for the Social Sciences (SPSS, version 20) for Windows. A $p$ value of 0.05 was used to determine any statistically significant difference.

\section{Results}

One hundred and twenty-three patients with type 2 diabetes were enrolled. There were 43 (35\%) males and 80 (65\%) females. The mean ages of the male and female participants were 57.8 and 55.2 years, respectively. The mean BMI of the males and females were 24.39 and $25.2 \mathrm{~kg} / \mathrm{m}^{2}$, respectively. Ninety percent of the study population was Singhalese with the remaining $10 \%$ comprising Tamils and Muslims. The socio-demographic profile of the study population is shown in Table 1. All participants of our study consumed a portion-restricted traditional meal, and there were no instances of meals that were culturally alien.

The mean daily consumption versus recommended intake Ninety-two percent of all diabetes patients (93\% of males and $91 \%$ of females) exceeded the lower recommended value of 6 servings of starch per day, and $43 \%$ of all participants (53\% of males and $38 \%$ of females) exceeded the upper recommended value of 11 servings per day. Twenty-five percent of the men consumed more than 14 servings of starch per day, but only $6 \%$ of the females exceeded this value.

The mean daily consumption of fruits and vegetables were 1.3 and 2.8 servings. Only $27 \%$ of the participants ( $25 \%$ of males and $27 \%$ of females) consumed the minimum recommendation of 2 servings of fruits per day,

Table 1 Demographic characteristics and BMI of the sample of diabetic patients

\begin{tabular}{|c|c|c|c|c|}
\hline \multirow[t]{2}{*}{ Variable } & \multicolumn{2}{|l|}{ Males (n 43) } & \multicolumn{2}{|c|}{ Female (n 80) } \\
\hline & Mean or \% & SD or $n$ & Mean or \% & SD or $n$ \\
\hline Age (years) & 57.84 & 12.49 & 55.29 & 10.39 \\
\hline \multicolumn{5}{|l|}{ Ethnicity } \\
\hline Sinhalese & $90.69 \%$ & 39 & $87.5 \%$ & 70 \\
\hline Muslim & $4.65 \%$ & 2 & $11.25 \%$ & 9 \\
\hline Sri Lankan Tamil & $2.32 \%$ & 1 & $1.25 \%$ & 1 \\
\hline Indian Tamil & $2.32 \%$ & 1 & $0 \%$ & 0 \\
\hline \multicolumn{5}{|l|}{ Education level } \\
\hline No schooling & $9.3 \%$ & 4 & $5 \%$ & 4 \\
\hline Up to 5 years & $11.62 \%$ & 5 & $15 \%$ & 12 \\
\hline Up to 11 years & $60.46 \%$ & 26 & $55 \%$ & 44 \\
\hline Up to 13 years & $16.27 \%$ & 7 & $22.5 \%$ & 18 \\
\hline Graduate & $2.3 \%$ & 1 & $2.5 \%$ & 2 \\
\hline BMI $\left(\mathrm{kg} / \mathrm{m}^{2}\right)$ & 24.34 & 3.85 & 25.14 & 3.99 \\
\hline
\end{tabular}

and only $45 \%$ of the participants consumed the minimum recommendation of 3 servings of vegetables per day. At least $62 \%$ of the study population consumed the recommended 2 servings of meat or alternative while consumption of pulses meeting the recommended 2 servings was only in $38 \%$ of the population. No dairy products were consumed by $23 \%$ of the sample. Consumption of added sugars was minimal with a mean consumption of 0.1 serving per day.

Cereals or derivatives of cereals accounted for the major portion of the carbohydrates among Sri Lankan diabetes patients. The 10.5 servings of starch were evenly distributed between breakfast, lunch and dinner by $3.3,3.5$ and 3.2 servings, respectively. The morning and evening snacks accounted for 0.3 and 0.5 servings of starch only. Vegetables and fruits were more abundantly used at lunch compared to breakfast or dinner. The study did not record the type of rice consumed by the participants. The breakdown of the number of servings of the seven food categories between the main meals is illustrated in Table 2.

Of the individual food types that contributed to daily carbohydrate intake (cereals, bread, traditional cerealbased food and pulses), the proportion contributed to by the staple, rice was $93 \%$. This is the single largest component of the diet in keeping with the traditional eating habits. None of the patients reported issues of palatability of the meal in modifying it to suit diabetes.

\section{Discussion}

The Sri Lankan traditional dietary pattern is centred on the 3 main meals of breakfast, lunch and dinner. It is customary to have tea with added milk on waking up and 2 other snacks in mid morning and afternoon. The traditional meal consists of three fourths of a plate of rice and the remainder consisting of vegetables and meat in the form of curries [7]. Fresh fruits are often used for dessert, and the traditional use of uncooked raw vegetables is rare.

Adult non-diabetic Sri Lankans on average consume 14.1 servings starch daily. National and international guidelines recommend 6-11 servings of starch per day, for healthy adults. The mean daily consumption of fruits and vegetables is low ( 0.4 and 1.7 servings, respectively), well below the recommended 2 and 3 servings per day [7]. National data reflect an upward trend in the per capita consumption of rice, from $86.8 \mathrm{~kg}$ in 1973 to $116 \mathrm{~kg}$ in 2007, with $90 \%$ of the consumption being white rice [8].

In most instances, there is no specific set amount of carbohydrates and other food types for diabetes, but these should be individualized and should fall within the recommendations made for healthy non-diabetic adults [6]. Most guidelines including the Sri Lankan national 
Table 2 Averaged total daily number of servings and the breakdown of each food category between meals

\begin{tabular}{|c|c|c|c|c|c|c|c|c|c|}
\hline \multirow{2}{*}{$\begin{array}{l}\text { Food group } \\
\text { (servings) }\end{array}$} & \multicolumn{2}{|l|}{ Daily } & \multirow[t]{2}{*}{ Morning tea } & \multirow[t]{2}{*}{ Breakfast } & \multirow{2}{*}{$\begin{array}{l}\text { Morning } \\
\text { snack }\end{array}$} & \multirow[t]{2}{*}{ Lunch } & \multirow{2}{*}{$\begin{array}{l}\text { Evening } \\
\text { snack }\end{array}$} & \multirow[t]{2}{*}{ Dinner } & \multirow{2}{*}{$\begin{array}{l}\text { After } \\
\text { dinner }\end{array}$} \\
\hline & Mean & SD & & & & & & & \\
\hline Starch & 10.5 & 3.6 & 0 & 3.4 & 0.3 & 3.1 & 0.5 & 3.2 & 0.1 \\
\hline Vegetables & 2.9 & 1.6 & 0 & 0.7 & 0 & 1.3 & 0 & 0.8 & 0 \\
\hline Fruits & 1.3 & 2.2 & 0 & 0 & 0.4 & 0 & 0.7 & 0 & 0.2 \\
\hline Meat or alt & 1.3 & 1.2 & 0 & 0.3 & 0 & 0.4 & 0 & 0.6 & 0 \\
\hline Pulses & 0.8 & 1.1 & 0 & 0.3 & 0 & 0.3 & 0 & 0.2 & 0 \\
\hline Dairy products & 0.4 & 0.3 & 0.3 & 0 & 0.1 & 0 & 0.1 & 0 & 0 \\
\hline Added sugar & 0.1 & 0.6 & 0 & 0 & 0 & 0 & 0 & 0 & 0 \\
\hline
\end{tabular}

guidelines recommend the lower value of the recommendation intended for healthy adults.

In our study, the mean daily consumption of starch alone was 10.5 servings (SD 3.6), fruits 1.3 servings (SD 2.2 ), vegetables 2.8 servings (SD 1.56) and pulses 0.83 servings (SD 1.1). A comparison of our results with the national and international guidelines for healthy adults is given in Table 3 .

However, we found that $92 \%$ of the participants still exceeded the recommended 6 servings of starch per day and that $43 \%$ exceeded the upper margin of 11 servings. Little evidence is available on the effect of rice consumption on the outcomes of diabetes and blood glucose control in established diabetes. However, the available evidence suggests high carbohydrate will increase postprandial blood glucose and triglyceride levels and promote weight gain [9]. In the present study, we found a very high reliance on the staple rice for the daily requirement of carbohydrate in keeping with findings of Jayawardena et al. although the number of mean servings had decreased from 14 to 10.5 . This is probably culturally mediated, and health education seems to have been only effective in reducing the portion size. Table 4 illustrates the percentage of participants together with the number of servings consumed from each food category and its relevance to accepted guidelines.

We observed a considerable improvement in the consumption of fruits and vegetables with an average daily intake of 1.3 and 2.8 servings, respectively. However, this still fell short of the recommended minimum of 2 and 3 portions of fruits and vegetables, with $33 \%$ not consuming any fruit and 4\% not consuming any vegetable. However, the benefits of adding both these components to a traditional rice meal have shown beneficial effects on diabetes control.

Kameyama et al. found that addition of vegetables to white rice-based meal reduced the postprandial glucose in healthy Japanese men [10]. These meals were considerably similar to the ones we encountered in our study population.

Similarly, consumption of a high-fruit diet showed a tendency towards improvement in $\mathrm{HbA} 1 \mathrm{C}$, and the addition of beans to rice showed an improvement in postprandial glucose in patients with type 2 diabetes $[5,11]$. Hettiarachchi found the glycaemic response of rice-based Sri Lankan meals to be lower in the presence of fibre [12], a constituent of both fruits and vegetables.

There is an encouraging trend towards the use of more fruits and vegetables albeit a large fraction $(74 \%$ and $65 \%$ ) still not consuming the recommended daily minimum. We did not look into the causes that limited the use of these 2 components. This is indeed surprising as both these components are readily available. However, the seasonal variation of availability, the high prices of some fruits may contribute to the low consumption [7]. This may be particularly true in our study as the

Table 3 Comparison of the average food intake of diabetic patients with national and international recommendations

\begin{tabular}{|c|c|c|c|}
\hline Food group & $\begin{array}{l}\text { US recommendations }{ }^{\dagger} \\
\text { (portions/day) }\end{array}$ & $\begin{array}{l}\text { National recommendations }{ }^{t+} \\
\text { (portions/day) }\end{array}$ & $\begin{array}{l}\text { Average intake of diabetic patients } \\
\text { (portions/day) }\end{array}$ \\
\hline Starch & $6-11$ & $6-11$ & 10.5 \\
\hline Fruits & $2-4$ & $2-3$ & 1.3 \\
\hline Vegetables & $3-5$ & $3-4$ & 2.9 \\
\hline Meat and pulses & $2-3$ & $1-2$ & 2.1 \\
\hline Dairy & $2-3$ & $1-2$ & 0.4 \\
\hline Added sugars & Sparingly & low & 0.1 \\
\hline
\end{tabular}

${ }^{\dagger}$ US Department of Agriculture (1992) The Food Guide Pyramid. Home and Garden Bulletin no. 252. Washington, DC: USDA Center for Nutrition Policy and Promotion.

${ }^{+\dagger}$ Nutrition Division Ministry of Health (2011) Food Based Dietary Guidelines for Sri Lanka, 2nd ed Colombo. 
Table 4 Percentage distribution of the servings from each food category within the participants

\begin{tabular}{|c|c|c|c|c|}
\hline Food group & $\begin{array}{l}\text { No. of } \\
\text { portions/day }\end{array}$ & All adults (\%) & Males (\%) & Females (\%) \\
\hline \multirow[t]{3}{*}{ Starch } & $>11$ & 43.08 & 53.48 & 37.5 \\
\hline & $\geq 6$ & 91.86 & 93.01 & 91.25 \\
\hline & $<6$ & 8.1 & 6.9 & 8.75 \\
\hline \multirow[t]{4}{*}{ Vegetables } & 0 & 4.06 & 4.6 & 3.75 \\
\hline & $>0$ and $<1$ & 4.06 & 4.6 & 3.75 \\
\hline & $1-3$ & 45.52 & 46.51 & 45 \\
\hline & $>3$ & 46.41 & 44.18 & 47.5 \\
\hline \multirow[t]{4}{*}{ Fruits } & 0 & 33.33 & 34.88 & 32.5 \\
\hline & $>0$ and $<1$ & 12.19 & 6.9 & 15 \\
\hline & $1-2$ & 27.64 & 32.55 & 25 \\
\hline & $>2$ & 26.82 & 25.58 & 27.5 \\
\hline \multirow[t]{4}{*}{ Meat or alt. } & 0 & 24.39 & 30.23 & 21.25 \\
\hline & $>0$ and $<1$ & 13 & 9.3 & 15 \\
\hline & $1-2$ & 26.82 & 20.93 & 30 \\
\hline & $>2$ & 35.77 & 39.53 & 33.75 \\
\hline \multirow[t]{5}{*}{ Pulses } & 0 & 43.08 & 39.53 & 45 \\
\hline & $0-1$ & 17.88 & 9.3 & 22.5 \\
\hline & $1-2$ & 22.76 & 27.9 & 20 \\
\hline & $2-3$ & 12.19 & 16.27 & 10 \\
\hline & $>3$ & 4.06 & 6.9 & 2.5 \\
\hline \multirow[t]{4}{*}{ Dairy products } & 0 & 22.76 & 16.27 & 26.25 \\
\hline & $0-1$ & 69.1 & 76.74 & 65 \\
\hline & $1-2$ & 8.1 & 6.97 & 8.75 \\
\hline & $>2$ & 0 & 0 & 0 \\
\hline \multirow[t]{3}{*}{ Added sugar } & 0 & 99.18 & 97.67 & 1 \\
\hline & $0-1$ & 0 & 0 & 0 \\
\hline & $>1$ & 0.81 & 2.32 & 0 \\
\hline
\end{tabular}

participants were mostly from a semi-urban background. Consumption of added sugar had decreased from 3.5 servings a day to 0.1 serving with counselling. Therefore, the exact reason for the low consumption of fruits and vegetables still remains unclear.

On the other hand, all our patients found their meals to be culturally acceptable and retain palatability while being adapted to suit diabetes.

A particular problem encountered in counselling is the translation of the energy requirements from each food category, expressed as proportion of the daily energy requirement, in guidelines into the everyday parlance of the patient. This is made more difficult due to cultural and ethnic differences in diet even among patients in the same locality. Therefore, we stress the need to develop local dietetic committees that could translate guidelines into measures of locally sourced food groups for everyday care of diabetes.

\section{Conclusions}

We confirm that the diet consumed by a majority of diabetic patients in our study was a portion-restricted version of the typical, locally sourced Asian diet that could still be shared with the rest of the family.

However, there is an excessive consumption of starch with rice predominance with poor consumption of fruits and vegetables. Portion restriction of rice and encouraging larger portions of fruit and vegetables as sources of carbohydrates and other micro-nutrients may improve the quality of the diet while retaining its traditional composition in this population.

\section{Abbreviation \\ ADA: American Diabetes Association. \\ Competing interests \\ The authors declare that they have no competing interests.}

\section{Authors' contributions}

AM was involved in the conception, planning, data collection, analysis and writing of the manuscript. HW was involved in the data collection, analysis and preparation of the manuscript. Both authors read and approved the final manuscript.

\section{Acknowledgements}

The authors wish to thank Dr. Ameena Suleiman for the assistance received in collecting the data.

\section{Received: 10 October 2014 Accepted: 27 January 2015}

Published online: 09 March 2015

\section{References}

1. Imam MU, Azmi NH, Bhanger MI, Ismail N, Ismail M. Antidiabetic properties of germinated brown rice: a systematic review. Evid Based Complement Alternat Med. 2012:2012:816501

2. Hu EA, Pan A, Malik V, Sun Q. White rice consumption and risk of type 2 diabetes: meta-analysis and systematic review. BMJ. 2012;344:e1454.

3. Katulanda P, Constantine GR, Mahesh JG, Sheriff R, Seneviratne RD, Wijeratne $\mathrm{S}$, et al. Prevalence and projections of diabetes and pre-diabetes in adults in Sri Lanka_-Sri Lanka Diabetes, Cardiovascular Study (SLDCS). Dia Med. 2008;25(9):1062-9.

4. Illangasekera U, Rambodagalla S, Tennakoon S. Temporal trends in the prevalence of diabetes mellitus in a rural community in Sri Lanka. J R Soc Promot Heal. 2004;124(2):92-4.

5. Thompson SV, Winham DM, Hutchins AM. Bean and rice meals reduce postprandial glycemic response in adults with type 2 diabetes: a cross-over study. Nutr J. 2012;11:23.

6. Evert AB, Boucher JL, Cypress M, Dunbar SA, Franz MJ, Mayer-Davis EJ, et al. Nutrition therapy recommendations for the management of adults with diabetes. Diabetes Care. 2013;36(11):3821-42.

7. Jayawardena R, Byrne NM, Soares MJ, Katulanda P, Hills AP. Food consumption of Sri Lankan adults: an appraisal of serving characteristics. Public Health Nutr. 2013;16(4):653-8.

8. D.P.C. Swarnasiri PJS. Quality evaluation of locally available rice in local market. Anuradhapura Sri Lanka: Institiute of Post Harvest Technology Sri Lanka Symposium 2012; 2012.

9. Ahn HJ, Eom YK, Han KA, Kwon HR, Kim HJ, Park KS, et al. The effects of small sized rice bowl on carbohydrate intake and dietary patterns in women with type 2 diabetes. Korean Dia J. 2010:34(3):166-73.

10. Kameyama N, Maruyama C, Matsui S, Araki R, Yamada Y, Maruyama T. Effects of consumption of main and side dishes with white rice on postprandial glucose, insulin, glucose-dependent insulinotropic polypeptide 
and glucagon-like peptide-1 responses in healthy Japanese men. Br J Nutr. 2014;111(9):1632-40

11. Christensen AS, Viggers L, Hasselstrom K, Gregersen S. Effect of fruit restriction on glycemic control in patients with type 2 diabetes-a randomized trial. Nutr J. 2013;12:29.

12. Hettiaratchi UP, Ekanayake S, Welihinda J. Sri Lankan rice mixed meals: effect on glycaemic index and contribution to daily dietary fibre requirement. Malaysian J Nutr. 2011:17(1):97-104.

Submit your next manuscript to BioMed Central and take full advantage of:

- Convenient online submission

- Thorough peer review

- No space constraints or color figure charges

- Immediate publication on acceptance

- Inclusion in PubMed, CAS, Scopus and Google Scholar

- Research which is freely available for redistribution 